\title{
Conflict Interpretation: A Comparison of Canadian and Italian Aggressive and Non-Aggressive Youth
}

\author{
Andrea Smorti \\ Enrica Ciucci \\ University of Florence \\ Anne McKeough \\ Jennifer Malcolm \\ Dawn Bremner \\ University of Calgary
}

\begin{abstract}
The impact of persistent aggression on youths' social and psychological well being is well documented. What is less well understood is the shaping effect of cultural differences on how such conflict is experienced and responded to. In this study, we asked youth to write a story about a conflict they experienced and describe their associated feelings. Participants included Canadian and Italian girls and boys from grades 4 and 7 who were rated by their teachers as either aggressive or non-aggressive. Results indicated that although there were no significant main effects for behavioural group or country in the description of the conflict, significant differences appeared in participants' descriptions of associated feelings. Specifically, non-aggressive participants were significantly better at generating psychological interpretions of actors' intentions and experienced significantly more congruent associated feelings. Additionally, Canadian participants were significantly better than Italian participants in generating psychological interpretation of conflicts.
\end{abstract}

\section{Aggression in Youth}

Over the past two decades, research on youth aggression has increased dramatically. This increase has occurred partially in response to societal concerns that particular types of youth aggression and violence are increasing (Bongers, Koot, van der Ende, \& Verhulst, 2004; Groves, 1997) and partially in response to the bleak outlook for many youth whose aggressive behaviours persist (Broidy et al., 2003; Card, Stucky, Sawalani, \& Little, 2008; Coie \& Jacobs, 1993; McMahon \& Wells, 1998). The considerable impact of aggressive behaviour makes it an important area of investigation. The goal of this study, in global terms, was to further our understanding of youth aggression by examining it through the lens of narrative psychology. 
Although physical aggression (e.g., hitting or pushing) generally decreases from toddlerhood to adolescence, a subset of youngsters maintain their aggressive behaviours and, because of their increased capacity to inflict harm, pose an increased threat to their victims (Broidy et al., 2003; Loeber \& Hay, 1997). Moreover, research has shown that although physical aggression decreases, relational aggression tends to increase with age (Crick et al., 2006). Persistent aggressive behaviour negatively influences the development of children, causing them to be at risk for a number of concurrent and long-term adjustment difficulties including academic failure, school dropout, adolescent delinquency, and adult criminality (Broidy et al., 2003; Heilbron \& Prinstein, 2008).

Research into factors that underlie aggressive behaviour has determined that aggressive children can have social cognitive deficits and that the relationship between social cognitions and externalizing behaviours is stronger in older than in younger children (Lansford et al., 2006). Dodge (1991) found that aggressive children tend to interpret ambiguous situations (i.e., situations in which the intentions of others are unclear) as aggressive and accordingly act aggressively towards others. Not surprisingly, children who view these forms of aggression and violence as justified are more likely to engage in aggressive behaviours (Calvete, 2008). Aggressive youths' peer groups reject them over time so the chances of learning prosocial alternatives are further reduced (Ladd, 2006). Their isolation, in turn, provides social cues that the environment is indeed hostile. This attributional bias becomes a perpetual circle of aggressive behaviour and negative peer reactions that serve to maintain their use of aggressive behaviours (Dodge, 1991).

\section{Narrative Framework}

Narrative psychology offers a useful framework for analyzing and interpreting youths' understanding of and motivation for aggression. Narratives tell of past events, set the stage for interpreting future events, and provide information regarding future expectations (Polkinghorne, 1988). Through the construction of stories, we assign meaning to the actions of others (Polkinghorne, 1988). As such, stories serve as templates for understanding the complexities of human interaction and increase our understanding of individuals' beliefs and expectations (Smorti, 2004).

The narrative mode of thought is based upon the temporal and causal ordering of two types of events: those that take place in the physical world, which Bruner (1986) refered to as the landscape of action, and those that take place in the mental life of the character, which Bruner refers to as landscape of consciousness. On the one hand, by examining the action antecedent to an event one is able to make sense of why the event occurred (e.g., the girl hit the boy because he hit her first). On the other hand, when an action is interpreted in terms of characters' psychological characteristics and their states of mind, meaning is made through the landscape of consciousness (e.g., the girl hit the boy because she refused to be pushed around). Here, the girl's behaviour is understood in terms of her psychological makeup.

Considerable research has demonstrated that narrative thought develops across the life span. To illustrate, when supported by adults, the ability to conceptualize the world in the form of verbal narrative emerges as early as 3 or 4 years of age (Fivush \& Haden, 2003; Nelson \& Fivush, 2004). By 4 years of age, children tell action-focused stories that include a sequence of events organized temporally, with little or no reference to the mental states of the characters beyond the global feelings associated with the social script (e.g., happy ever after). Between 6 
and 10 years of age, children's stories become increasingly intentional. That is, children produce stories where characters' intentions motivate their actions (e.g., the little girl asked her mom to sleep with her because she wanted company; McKeough, 1992). In adolescent narrative thought, these intentions, along with other mental states, are interpreted in psychological terms. For example, an individual's mental states or traits are explained in terms of his or her personal histories (e.g., the girl didn't trust her teacher because of the cruelty she experienced in boarding school; McKeough \& Genereux, 2003).

\section{Aggressive Youth and Developmental Change in Narrative Thought}

Narrative frameworks have been used to examine developmental change in social cognition within and across cultures. To illustrate, McKeough, Yates, and Marini (1994) examined these developmental changes in the narratives of boys clinically diagnosed with behavioural disorders and compared them to a non-aggressive, typically functioning sample. The aggressive group's stories were less intentional (i.e., included fewer mental states) and less socially appropriate than those of the non-aggressive group, indicating differences in participants' representations of social contexts.

Narrative thought is not always delayed in aggressive youth, however. When Smorti and Ciucci (2000) examined the narrative strategies of bullies and victims, they determined that bullies typically used both action and mental states to interpret socially incongruent narratives (i.e., narratives in which the response of a character did not match the socially expected response), whereas victims tended to rely solely on actions when interpreting their socially incongruent narratives. The authors suggested that bullies use both types of events in their interpretations in order to justify their actions, whereas victims rely on external action as the cause of the aggression, which protects the victim's sense of self in that he or she is neither responsible for nor has control over the situation. These results are notable in that they reveal a unique pattern of response for a subset of aggressive and non-aggressive youth (i.e., bullies and victims) who were not clinically diagnosed as behaviourally disordered.

\section{Cultural Differences in Narrative Thought}

Unique patterns of narrative thought have long been noted across cultures (Bruner, 1986). Narrative creates culture as it is through narrative that we represent our beliefs and values and pass them on. In turn, individuals within the culture use the narratives to make personal meaning (Fox, 1997; Greenfield, Keller, Fuligni, \& Maynard, 2003; Han, Leichtman, \& Wang, 1998). In constructing personal narratives, the storyteller reshapes experiences to fit with a system of values drawn from his or her socio-cultural base (Fox, 1997; Nelson, 2003).

Culture is explicitly embedded in narrative through the themes and principles expressed in the stories, the meaning we attribute to experience (Amsterdam \& Bruner, 2000; Markus \& Kitayama, 1991), and the discourse patterns between children and parents (Adams \& Markus, 2001). To illustrate, an independent self-orientation, which emphasizes inner attributes and selfexpression is evident in Western societies, whereas interdependence is favoured in Asian cultures where connection and belonging define the self (Markus \& Kitayama, 1991).

Yet within these global orientations, differences exist. To illustrate, although Italian and Canadian cultures fall within the Western category, they differ on a number of dimensions. First, 
despite the overall individualism evident in social life outside of the family, Italians' involvement with extended family remains an important determinant of identity (Schneider, Fonzi, Tani, \& Tomada, 1997). English Canadians, in comparison, have been found to be more individualistic both within and outside of the family (Baer, Grabb, \& Johnston, 1990). Second, the priority of peer relationships has also been found to differ between Italian and Canadian parents. Specifically, Canadian mothers gave higher priority to peer relationships and were more concerned about social withdrawal than were Italian mothers, who felt more ambivalent about their children's peer relations (Schneider, Fonzi, et al., 1997). Lambert, Hamers, and FraserSmith (1979) also determined that Italians showed ambivalence toward extra-familial peer relationships. In contrast to the United Kingdom and Japan, Italians indicated that rules for peer relationships were flexible and they tended to be inconsistent among themselves in indicating what rules existed. Thus, as narrative thought is both a function of culture and a creator of culture, narratives provide a unique means of evaluating cross-cultural differences (Smorti et al., 2007).

Cultural difference in aggression. Differences in representation and expression of conflict also exist between Asian and Western cultures. Specifically, differences have been identified in Japanese and American school children's responses to hypothetical interpersonal dilemmas (Zahn-Waxler, Friedman, Cole, Mizuta, \& Hiruma, 1996). American children exhibited more aggressive behaviour and language than Japanese children and were less adept at self-regulating emotional responses, possibly due to parenting styles. Within Western cultures differences have been identified, as well. Italian adolescents displayed more negative feelings and tolerated and expected the expression of aggression more than other Western countries (Argyle, Henderson, Bond, Iizuka, \& Contarello, 1986), and they reported more conflict with their parents than Canadian and French adolescents (Claes, Lacourse, Bouchard, \& Perucchini, 2003). Yet when compared to young Canadian adolescents, Italians tended to diminish an aggressive peer's responsibility by searching for possible causes in the environment. In contrast, Canadians youth identified the person's intention as the cause of the aggression. This different response to family and non-family members might well reflect the Italian parental ambivalent attitudes toward extra-familial relations (Lansford et al., 2007; Schneider, Attilli, Vermigli, \& Younger, 1997).

\section{The Present Study}

The aim of the present research was to investigate potential differences in aggressive and non-aggressive youths' interpretation of interpersonal conflict narratives. Aggressive and nonaggressive youth were chosen because they have been found to exhibit different patterns of social cognition and narrative thought. Italian and Canadian participants were chosen because these two Western countries differ on critical dimensions (e.g., display, tolerance, and cause of aggression). Finally, grades 4 and 7 students were chosen for the study as it has been demonstrated that important developmental change occurs in narrative thought over this period (Case, 1992; McKeough \& Genereux, 2003), suggesting that these are reasonable points to examine potential differences between the two groups (i.e., aggressive and non-aggressive) and countries (i.e., Canada and Italy). 


\section{Method}

\section{Participants}

Two hundred and seventeen volunteers were recruited from classrooms in large urban centres in Canada $(n=97)$ and Italy $(n=120)$. The sample included 123 non-aggressive and 94 aggressive children. There were 103 boys and 114 girls in the sample, distributed across grades 4 $(n=121)$ and $7(n=96)$. The Canadian sample was enrolled in a publicly funded separate school board, whereas the Italian sample was enrolled in the public school system.

Behavioural group assignment was based on teacher ratings on the Behavior Checklist for Children: Teacher's Version (Caprara \& Laeng, 1988). The instrument was administered and scored in a standardized fashion, as stipulated by the test developers. To ensure clear differentiation between the behaviourally aggressive and non-aggressive children, the following criteria were established. Students whose scores placed them above the $75^{\text {th }}$ percentile on the Aggression Scale and below the $25^{\text {th }}$ percentile on the Prosocial Scale were identified as behaviourally aggressive. Those who fell below the $50^{\text {th }}$ percentile on the Aggression Scale and above the $50^{\text {th }}$ percentile on the Prosocial Scale were identified as non-aggressive. Students who fell outside these parameters were not included in this study. To control for possible deficits in participants' cognitive or intellectual skills and oral and written language, participants whose standardized achievement scores indicated that they were functioning two or more grade levels below their placement were excluded from the sample. The two behavioural groups were matched according to scholastic ability, parents' level of education, and socioeconomic status (SES). For the Canadian sample, the National Occupation Classification System (Employment \& Immigration Canada, 1993) was used to estimate the parents' SES. For the Italian sample, SES was estimated using the ISTAT tables on Parents' Level of Occupation and Education in Italy (National Institute of Statistics, 1990). Estimated SES was based on the average projected income and education attainment for members in the same occupation as those cited by the parents. A one-way analysis of variance found no significant SES differences between the grades or the aggressive and non-aggressive groups.

\section{Measures}

Behavior Checklist for Children: Teacher's Version. This checklist (Caprara \& Laeng, 1988) is composed of two scales: a physical and verbal aggression scale (A) and a prosocial behaviour scale (P). The A scale is a 20-item, 3-point scale (often $=3$, sometimes $=2$, never $=1$ ) including five control items. The items offer a description of behaviour involving hurting others physically and verbally. The $\mathrm{P}$ scale is a 15 -item, 3-point scale (often $=3$, sometimes $=2$, never $=1$ ) including five control items. The items identify behaviour involving altruism, trust, and agreeableness. These scales have been previously applied using Italian, Hungarian, and Czech samples and have demonstrated good internal consistency and concurrent validity (Caprara \& Pastorelli, 1993; Pastorelli, Barbaranelli, Cermak, Rozsa, \& Caprara, 1997). These studies were replicated on several Italian samples (north, south, and central Italy), substantially confirming the internal consistency of each scale. Predictive validity was established in a longitudinal study that found aggression to be predictive of later personality dispositions (e.g., irritability) and prosocial behaviour to be negatively correlated to all personality traits related to aggression and violence (Pastorelli, Incatasciato, \& Rabasca, 1994). 
Conflict story. Participants were asked to write about a school-related conflict situation that they had been involved in, been witness to, or had heard about. Participants were given 30 minutes to complete this personal conflict story in class. The following instructions were provided both in written and oral form:

I want you to write a story about a time when you or one of your classmates was involved in a problem situation at school that needed to be solved. Maybe you were there when it happened, so that you actually saw it happening, or maybe you just heard about it a bit later. The situation might have happened in your classroom, somewhere else in the school, or around the school. You can decide how long your story will be, but please make sure you describe the situation in enough detail that a stranger, who might be reading your story, will be able to understand what happened.

Personal response question. Upon completing their stories, participants answered the following question: When you saw the problem situation happen or when you heard about it, what did you think or feel? Try to think back to the situation and tell as much as possible about your different thoughts and feelings then.

\section{Procedure}

Following ethical clearance in each country, volunteer participants were recruited through schools. Information explaining the purpose of the research and participants' involvement was outlined in a letter to teachers, which was read to potential participants. Students who indicated interest were provided with a fuller explanation of the research that they shared with their parents. Students and parents were informed that participants could withdraw from the study at any time without penalty. Students whose parents permitted them to participate, as indicated by their signature on a permission letter, were included as potential participants. Teachers rated participants to determine behavioural group membership. Italian teachers used the Italian version of the instrument whereas Canadian teachers used the English version. All participants were asked first to write a conflict story and second to write their response to the conflict. Italian participants wrote in Italian and Canadian participants wrote in English.

\section{Scoring}

Participants' responses were analyzed using two scoring procedures. First, an analysis of developmental complexity was undertaken on both the conflict story and personal response question. Subsequently, an analysis of the congruency between the conflict, as represented in the conflict story, and the participant's feeling about the conflict, as represented in the personal response to the conflict (i.e., story conflict/personal response congruency), was conducted.

Developmental complexity. A three-step procedure was followed. First, the conflict stories were broken into terminable units or T-units (i.e., the shortest grammatically correct clauses that a written passage can be broken into without creating fragments; Hunt, 1977), which served as the basic unit for the analysis. Second, each T-unit was scored for complexity of meaning by categorizing it as either action/descriptive, intentional, or interpretive, following the major shifts in narrative organization (McKeough \& Genereux, 2003; see Appendix). Third, the proportion of action/descriptive, intentional, and interpretive T-units was calculated and three scores assigned to each participant. 
The personal response question was scored using the same analysis. However, because participants' statements were quite short, resulting in fewer T-units, participants were assigned only one score that reflected the highest-level T-unit produced (i.e., action/descriptive, intentional, or interpretive).

Story conflict/personal response congruency. Answers to the personal response question were rated as either "adaptive" or "maladaptive" according to whether or not the descriptions of the participants' thoughts and feelings were congruent with conflict described in the conflict story. Adaptive scores reflected that participants' answers were socially appropriate, whereas maladaptive ratings indicated that participants' responses were socially inappropriate. Scoring criteria for the congruency of feelings to the conflict situation are presented in Table 1.

\section{Results}

\section{Inter-rater Reliability}

The first step in data analysis was to ensure consistency across raters. This involved the principal investigators meeting first in Canada and then in Italy to train research assistants to score each of the two countries' data. Inter-rater reliability was established for each country and then across countries by comparing a subset of scores assigned by two independent raters, the second of whom was blind to participant information. For the Italian sample, Cohen's kappa varied from 0.75 to 0.90 , indicating a moderate to high agreement. For the Canadian sample, the coefficients varied from 0.70 to 0.90 , indicating a moderate to high agreement. Disagreements were resolved through discussion. To establish inter-rater reliability between countries, a subset of the protocols was analyzed by Canadian and Italian researchers. Cohen's kappa varied from 0.70 to 0.80 (Canadian sample protocols) and 0.65 to 0.75 (Italian sample protocols), indicating moderate to high agreement.

\section{Statistical Analysis}

A series of $2 \times 2$ ANOVAs was used to assess group and country differences on the developmental scoring of the conflict story and personal response question, as the sample size was deemed too small to run a MANOVA. The alpha rate was conserved at $p<.008$, using the Bonferroni adjustment factor for each set of analyses. No significant differences were noted between group or country on the developmental scoring for action/descriptive, intentional, or interpretive T-units for the conflict story.

Table 1

Scoring Criteria for Story Conflict/Personal Response Congruency

\begin{tabular}{lc}
\hline \multicolumn{1}{c}{ Thoughts and Feelings } & Rating \\
\hline Feeling bad about the conflict & Adaptive \\
Feeling sorry about the conflict & Adaptive \\
Disapproving of people in conflict & Adaptive \\
Feeling happy that actors were in conflict & Maladaptive \\
No reflecting or feeling response & Maladaptive \\
Wishing he had acted aggressively & Maladaptive \\
\hline
\end{tabular}


Analysis of the developmental scoring of participants' personal response to the conflict story was also conducted, with interpretive T-units as the dependent variable and behavioural group and country as the independent variables. The results indicated significant group, $F(1,202)$ $=7.63, p<.006$, and country, $F(1,202)=7.15, p<.008$, main effects. More specifically, the non-aggressive group $(M=2.29, S D=0.51)$ produced significantly more interpretive T-units (i.e., were significantly better at explaining the mental states of the individuals in their stories in psychological terms) than the aggressive group $(M=2.10, S D=0.40)$ and Canadian participants $(M=2.30, S D=0.48)$ produced significantly more interpretive T-units than Italian participants $(M=2.14, S D=0.46)$. Cohen's $d$ was calculated for all significant results to evaluate the magnitude of the effect size. The group effect was in the moderate range (Cohen's $d=.41$ to $.45)$, whereas the country effect size was in the small range (i.e., less than .40).

\section{Story Conflict/Personal Response Question Congruency}

Chi-square analyses were undertaken to explore group and country differences for the story conflict/personal response congruency ratings. Significant behavioural group effects were found (Chi-square $=14.293, p<.001$ ), with the non-aggressive group having more adaptive scores, $M=93.2$ (60.6) versus $M=72.7$ (59.5), and the aggressive group having more maladaptive scores, $M=27.30$ (59.5) versus $M=6.8(39.4)$.

\section{Discussion}

The first finding of the present study indicated that although there were no major differences between the aggressive and non-aggressive groups in the developmental complexity of the conflict story, per se, significant differences were found in their feeling response of the conflict situation they described. That is, the aggressive group's responses were less interpretive than those of the non-aggressive group, indicating that they were less able to account for their thoughts and feelings by, for example, making reference to their personal histories or psychological/social states. The implications of the aggressive participants having less capacity, compared to non-aggressive peers, to reflect on and analyze their feeling states toward interpersonal conflict are potentially highly problematic. Interpretive thought plays a critical role as youth develop autobiographical memory, which is central to the creation of a meaningful sense of self within a social context. Autobiographical memories define who we were and who we are, and give us a sense of purpose, unity, and identity (McLean \& Thorne, 2003). Throughout adolescence, youth become increasingly adept at understanding the interconnectedness of events in their lives through the creation of themes of experience, which include both time- and emotion-marked events (Nelson \& Fivush, 2004) that serve as an interpretive lens focused on the world and self (Habermas \& Bluck, 2000). Less interpretation of feeling states associated with conflict situations suggests that such themes are potentially impoverished. Without developmentally-typical themes, youth are less likely to self-monitor present behaviour and learn from past conflict, as awareness of one's feelings in situations provides important feedback, which in turn shapes future behaviour. The findings of the present study, moreover, supports extant research that has demonstrated that aggressive youth are less able to interpret social context (Crick \& Dodge, 1994; Lansford et al., 2006; McKeough et al., 1994) and are less adept at recognizing and interpreting their feeling states (Smorti et al., 2007). 
The second finding of the study was that there was a significant difference between the Canadian and Italian participants on their feeling response of the conflict situation they described. Narrative thought develops within the cultural context; the ways in which one constructs and tells of one's experiences is shaped by culture (Bruner, 1990). That Italian participants generated fewer interpretive T-units than the Canadian participants when reflecting on how they felt about the conflict might be explained by reference to previous research that has shown that Italians may be more comfortable with conflict and its associated negative feelings than other nationalities (Argyle et al., 1986; Attili, Vermigli, \& Schneider, 1997). It may be that the Italian participants needed to justify their thoughts, feelings, and intentions associated to conflict less than the Canadian participants, given a greater comfort with negative feelings. Additionally, it is plausible that Italian participants tend to explain aggressive actions in terms of environmental factors rather than actors' intentions (Smorti et al., 2007), resulting in less interpretation of mental states. Future research with larger samples is needed, however, to more fully explore the existence of cultural differences in the complexity of narrative thought.

The final analysis examined the congruency between the conflict described in the story and participants' personal response to it. In contrast with the developmental analysis, which measured cognitive complexity, the congruency analysis examined social adaptiveness. That the aggressive group's stories were more maladaptive, whereas those of the non-aggressive group were more adaptive, is reasonable in light of the extant literature. More specifically, aggressive children tend to justify aggressive acts, with the result that there is social incongruence between the act and their response to it (Calvete, 2008; Peets, Hodges, \& Salmivalli, 2008; Smorti \& Ciucci, 2000). This is exacerbated by their inability to accurately interpret their own motivations and feeling states (Smorti et al., 2007).

\section{Conclusions}

The results of the present study are noteworthy in that they add to the existing literature in several ways. First, distinguishing between describing a conflict situation, per se, and describing one's feelings toward it is an important one, especially in educational and treatment contexts. The present results suggest that teachers and therapists need to be aware of the social incongruency in aggressive youths' feeling response to conflict, and to support them by helping them explore and analyze the intentions that underlie interpersonal conflict (e.g., why about X made him feel so upset when Y teased him?). Second, differences found in the present study between Canadian and Italian participants demonstrate the subtle effects that a country's sociocultural orientation can have on youths' social worldview, thus highlighting the interplay between the developmental and socio-cultural factors that shape the thinking of youth. Finally, the present results move us closer to understanding the intricacies of narrative thought and its role in the social development of youth.

It is important to note, however, that the calculated effect sizes were in the small to medium range. More specifically, although country differences were found to be significant, the effect sizes were small, indicating the results may be sample specific. Additionally, because participants completed the measures in two languages, language is a potential confound, as is the case with all comparative cross-cultural research. Thus, further research is needed to ascertain the validity of these results. Additionally, the storytelling task, which asked participants to relate a story about a conflict that they had experienced, witnessed, or heard about, did not ensure that the degree of emotional intensity was consistent across stories. Although this is undoubtedly a 
limitation, it must be noted that the non-aggressive group, which research has shown experiences fewer aggressive interactions than the aggressive group (Dodge, 1991), demonstrated a greater propensity to explain the mental states of the individuals in the stories. Importantly, the opposite might reasonably be expected (i.e., fuller explanation might well be occasioned by more intense emotional response related to direct experience) if the task impacted performance. Moreover, a similar finding was found on the Story Conflict/Personal Response Congruency item. Nevertheless, further research should also continue to investigate the narratives of a range of aggressive and non-aggressive children to help further delineate the relationship between the severity of the problem and cognitive delays and changes in emotional and cognitive expression.

\section{References}

Adams, G., \& Markus, H. R. (2001). Culture as patterns: An alternative approach to the problem of reification. Culture and Psychology, 7(3), 283-296.

Amsterdam, A. G., \& Bruner, J. (2000). Minding the law. Cambridge, MA: Harvard University Press.

Annuario statistico italiano. (1990). ISTAT (Ed.), Rome, Italy.

Argyle, M., Henderson, M., Bond, M., Iizuka, Y., \& Contarello, A. (1986). Cross-cultural variations in relationship rules. International Journal of Psychology, 21(3), 287-315.

Attili, G., Vermigli, P., \& Schneider, B. H. (1997). Peer acceptance and friendship patterns among Italian schoolchildren within a cross-cultural perspective. International Journal of Behavioral Development, 21(1), 277-288.

Baer, D., Grabb, E., \& Johnston, W. A. (1990). The values of Canadians and Americans: A critical analysis and reassessment. Social Forces, 68(3), 693-713.

Bongers, I. J., Koot, H. M., van der Ende, J., \& Verhulst, F. C. (2004). Developmental trajectories of externalizing behaviors in childhood and adolescence. Child Development, 75(5), 1523-1537.

Broidy, L. M., Nagin, D. S., Tremblay, R. E., Bates, J. E., Brame, B., \& Dodge, K. A. (2003). Developmental trajectories of childhood disruptive behaviors and adolescent delinquency: A sixsite, cross-national study. Developmental Psychology, 39(2), 222-245.

Bruner, J. (1986). Actual minds, possible worlds. Cambridge, MA: Harvard University Press.

Bruner, J. (1990). Acts of meaning. Cambridge, MA: Harvard University Press.

Calvete, E. (2008). Justification of violence and grandiosity schemas as predictors of antisocial behavior in adolescents. Journal of Abnormal Child Psychology, 36, 1083-1095.

Caprara, G. V., \& Laeng, M. (1988). Behavior Checklist for Children: Teacher's Version. Rome: Bulzoni.

Caprara, G. V., \& Pastorelli, C. (1993). Early emotional instability, prosocial behavior and aggression: Some methodological aspects. European Journal of Personality, 7, 19-36.

Card, N. A., Stucky, B. D., Sawalani, G. M., \& Little, T. D. (2008). Direct and indirect aggression during childhood and adolescence: A meta-analytic review of gender differences, intercorrelations, and relations to maladjustment. Child Development, 79(5), 1185-1229.

Case, R. (1992). The mind's staircase: Exploring the conceptual underpinnings of children's thought and knowledge. Hillsdale, NJ: Erlbaum.

Claes, M., Lacourse, E., Bouchard, C., \& Perucchini, P. (2003). Parental practices in late adolescence, a comparison of three countries: Canada, France and Italy. Journal of Adolescence, 26(4), 387-399.

Coie, J. D., \& Jacobs, M. R. (1993). The role of social context in the prevention of conduct disorder. Development and Psychopathology, 5, 263-275.

Crick, N. R., \& Dodge, D. A. (1994). A review and reformulation of social information-processing mechanisms in children's social adjustment. Psychological Bulletin, 115(1), 74-101. 
Crick, N. R., Ostrov, J. M., Burr, J. E., Cullerton-Sen, C., Jansen-Yeh, E., \& Ralston, P. (2006). A longitudinal study of relational and physical aggression in preschool. Applied Developmental Psychology, 27, 254-268.

Dodge, K. A. (1991). The structure and function of reactive and proactive aggression. In D. J. Pepler \& K. H. Rubin (Eds.), The development and treatment of childhood aggression (pp. 210-218). Hillsdale, NJ: Lawrence Erlbaum.

Employment \& Immigration Canada. (1993). National occupation classification. Ottawa, ON: Canada Communication Group.

Fivush, R., \& Haden, C. A. (2003). Autobiographical memory and the construction of a narrative self: Developmental and cultural perspectives. Mahwah, NJ: Erlbaum.

Fox, R. (1997). Children and the development of narrative thought. In A. Smorti (Ed.), The self as text: Constructing of the self (pp. 256-262). Florence, Italy: Giunti.

Greenfield, P., Keller, H., Fuligni, A., \& Maynard, A. (2003). Cultural pathways through universal development. Annual Review of Psychology, 54, 461-490.

Groves, B. M. (1997). Growing up in a violent world: The impact of family and community violence on young children and their families. Topics in Early Childhood Special Education, 17(1), 74-102.

Habermas, T., \& Bluck, S. (2000). Getting a life: The emergence of the life story in adolescence. Psychological Bulletin, 26(5), 748-769.

Han, J. J., Leichtman, M. D., \& Wang, Q. (1998). Autobiographical memory in Korean, Chinese, and American children. Developmental Psychology, 34(4), 701-713.

Heilbron, N., \& Prinstein, M. J. (2008). A review and reconceptualization of social aggression: Adaptive and maladaptive correlates. Clinical Child and Family Psychology Review, 11(4), 176-217.

Hunt, K. W. (1977). Early blooming and late blooming syntactic structures. In C. Cooper \& L. Odell (Eds.), Evaluating writing: Describing, measuring, and judging (pp. 91-104). Urbana, IL: National Council of Teachers of English.

Ladd, G. W. (2006). Peer rejection, aggressive or withdrawn behavior, and psychological maladjustment from ages 5 to 12: An examination of four predictive models. Child Development, 77(4), 822846.

Lambert, W. E., Hamers, J. F., \& Fraser-Smith, N. (1979). Child rearing values: A cross-national study. New York: Praeger.

Lansford, J. E., Capanna, C., Dodge, K. A., Caprara, G. V., Bates, J. E., Pettit, G. S., et al. (2007). Peer social preference and depressive symptoms of children in Italy and the United States. International Journal of Behavioral Development, 3, 274-283.

Lansford, J. E., Malone, P. S., Dodge, K. A., Crozier, J. C., Pettit, G. S., \& Bates, J. E. (2006). A 12-year prospective study of patterns of social information processing problems and externalizing behaviors. Journal of Abnormal Child Psychology, 34, 715-724.

Loeber, R., \& Hay, D. (1997). Key issues in the development of aggression and violence from childhood to early adulthood. Annual Reviews in Psychology, 48, 371-410.

Markus, H. R., \& Kitayama, S. (1991). Culture and the self: Implications for cognition, emotion, and motivation. Psychological Review, 98(2), 224-253.

McKeough, A. (1992). A neo-structural analysis of children's narrative and its development. In R. Case (Ed.), The mind's staircase: Exploring the conceptual underpinnings of children's thought and knowledge (pp. 171-188). Hillsdale, NJ: Erlbaum.

McKeough, A., \& Genereux, R. (2003). Transformations in narrative thought during adolescence: The structure and content of story compositions. Journal of Educational Psychology, 95(3), 537-552.

McKeough, A., Yates, T., \& Marini, A. (1994). Intentional reasoning: A developmental study of behaviorally aggressive and normal boys. Development and Psychopathology, 6, 285-304.

McLean, K. C., \& Thorne, A. (2003). Late adolescents' self-defining memories about relationships. Developmental Psychology, 39(4), 635-645.

McMahon, R. J., \& Wells, K. C. (1998). Conduct problems. In E. J. Mash \& R. A. Barkley (Eds.), Treatment of childhood disorders (2nd ed., pp. 111-207). New York: Guilford Press. 
Nelson, K. (2003). Narrative and self, myth and memory: Emergence of the cultural self. In R. Fivush \& C. Haden (Eds.), Autobiographical memory and the construction of a narrative self: Developmental and cutural perspectives (pp. 3-28). Mahwah, NJ: Erlbaum.

Nelson, K., \& Fivush, R. (2004). The emergence of autobiographical memory: A social cultural developmental theory. Psychological Review, 111(2), 486-511.

Pastorelli, C., Barbaranelli, C., Cermak, I., Rozsa, S., \& Caprara, G. V. (1997). Measuring emotional instability, prosocial behavior and aggression in pre-adolescents: A cross-national study. Personality Individual Differences, 23(4), 691-703.

Pastorelli, C., Incatasciato, M., \& Rabasca, A. (1994). Precursori e correlati delle disposizioni di personalità connessi alla condotta aggressiva. Età Evolutiva, 49, 86-93.

Peets, K., Hodges, E. V. E., \& Salmivalli, C. (2008). Affect-congruent social-cognitive evaluations and behaviors. Child Development, 79(1), 170-185.

Polkinghorne, D. E. (1988). Narrative knowing and the human sciences. Albany, NY: State University of New York Press.

Schneider, B. H., Attilli, G., Vermigli, P., \& Younger, A. (1997). A comparison of middle class EnglishCanadian and Italian mother's beliefs about children's peer-directed aggression and social withdrawal. International Journal of Behavioral Development, 21(1), 133-154.

Schneider, B. H., Fonzi, A., Tani, F., \& Tomada, G. (1997). A cross-cultural exploration of the stability of children's friendships and the predictors of their continuation. Social Development, 6(3), 322339.

Smorti, A. (2004). Narrative strategies for interpreting stories with incongruent endings. Narrative Inquiry, 14(1), 141-167.

Smorti, A., \& Ciucci, E. (2000). Narrative strategies in bullies and victims in Italian schools. Aggressive Behavior, 26(1), 33-48.

Smorti, A., McKeough, A., Ciucci, E., Pyryt, M., Wilson, N., Sanderson, A., et al. (2007). Narrative strategies of aggressive and non-aggressive children: A cross-cultural comparison. Narrative Inquiry, 17(2), 23-42.

Zahn-Waxler, C., Friedman, R. J., Cole, P. M., Mizuta, I., \& Hiruma, N. (1996). Japanese and United States preschool children's responses to conflict and distress. Child Development, 67(5), 24622477.

\section{Authors' Notes}

Correspondence concerning this article should be addressed to Anne McKeough, Division of Applied Psychology, University of Calgary. Email: mckeough@ucalgary.ca 


\section{Appendix T-Unit Scoring Criteria for Conflict Story}

1) Action or descriptive T-units: Action T-units describe physical movement (e.g., "Sue got up and got ready to go to school."), whereas descriptive T-units give information concerning settings or physical states and events transcribed by a copula verb (e.g., "July $16^{\text {th }}$ was the day" and "she was deaf.").

2) Intentional T-units refer to first-order mental states: They can be expressed in four ways:

a. Thoughts, needs, wishes, and plans that motivate action (e.g., "She then decided to do just that.").

b. A social judgment that is context specific (e.g., "your (you're) doing all right for (as) a baseball player."), or describes a general social trait (e.g., "a nice boy") or social relation (e.g., "she was my friend").

c. Affectively laden verbs that describe emotion (e.g., "She was really scared.").

d. Actions or descriptions that suggest underlying mental states (e.g., "'Leave me alone!' she screamed." or "her cold shakey hand").

3) Interpretive T-units refer to second-order mental states that underlie first order mental states. They can be expressed in eight ways:

a. Justification of a mental state or social judgment with a second mental state or social judgment (e.g., "Joey loved pets [first order mental state] because he knew they wouldn't make fun of him"[second order mental state].). The initial clause, "Joey loved pets," would have been considered an intentional T-unit if it had stood alone. However, with the addition of the underlying motivation "because he knew they wouldn't make fun of him" the entire sentence is categorized as one interpretive T-unit.

b. Reflection on (or taking a metaposition to) the psychological cause and effect of (i) actions (e.g., "On my way home I was really upset. Maybe I was really stupid coming here. I tried to stop a problem and all I did was create another one."), (ii) mental states (e.g., "Joey hadn't realized that if he had told them earlier it would have been much easier to face the facts."), and (iii) social situations (e.g., "But remember there are always those few kids that are left out of everything, are loners and don't really care what they do. In other words, they're different than everyone else.").

c. Statements denoting self-understanding, self-knowledge, and self-questioning (e.g., "I was known to suck up to people. And now I know its true. Whenever someone was mad at me I would always be the first to apologize. Even if it wasn't my fault.").

d. Enduring psychological/social state or trait (e.g., "Teasing and nagging would always ring in his ears during the night.").

e. Psychological/social similes and metaphors (e.g., "So now it's like the whole world has closed up around me." and "The wall had started to build. Not a wall of concrete or stone but a mental wall that no one, except for Rachel herself, could move or tear down.").

f. Flashback and foreshadowing (e.g., "I thought about the first time I met her in grade one." and "That was one promise I wished I had kept.").

g. Paradoxical or conflicting consequences (e.g., "And poor Laurie. An innocent girl who got what she did not deserve... Things like this sometimes happen. Too often though.").

h. Perspective taking (e.g., "I am sixteen and mature enough to handle the responsibility of a vacation alone.' No. That would be no good it sounded too superior.") 